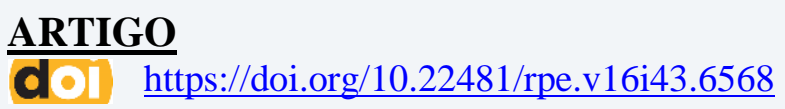

\title{
O MOVIMENTO DA DIDÁTICA CRÍTICA E O PENSAMENTO PEDAGÓGICO- DIDÁTICO NA DÉCADA DE 1980
}

\author{
THE CRITICAL DIDACTIC MOVEMENT AND PEDAGOGICAL-DIDACTIC THINKING \\ IN THE 1980’S
EL MOVIMIENTO DE LA DIDACTICA CRÍTICA Y EL PENSAMIENTO PEDAGÓGICO- DIDÁCTICO EN LA DÉCADA DE 1980

\section{Lenilda Rêgo Albuquerque de Faria}

Universidade Federal do Acre - Brasil

\begin{abstract}
Resumo: O artigo tem por objetivo analisar o movimento das proposições contra-hegemônicas, notadamente, nos anos de 1980, no contexto do movimento da didática crítica e suas repercussões epistemológicas no campo da pedagogia e da didática. Para tanto, examinamos algumas das mais expressivas produções no campo da didática que assumem o método dialético como método de investigação. No trato teórico-metodológico assumimos o entendimento de ser a Pedagogia a ciência da e para a prática educativa e a Didática, a teoria do ensino na sua totalidade e em seu movimento. Ao mesmo tempo optamos pela teoria do SER SOCIAL de Marx e de suas expressões na pedagogia histórico-crítica. Os resultados do estudo sinalizam que o movimento da didática crítica não foi apenas uma alternativa a pedagogia oficial, marcada pelo tecnicismo pedagógico, mas se contrapôs pela sistematização de orientações pedagógicas que fazem uma crítica rigorosa a perspectiva burguesa de escola, ao mesmo tempo que lutam pela democratização da escola pública, espaço privilegiado do conhecimento sistematizado, dos conteúdos historicamente desenvolvidos e sistematizados, pela valorização profissional dos professores e sua autonomia intelectual a partir do desenvolvimento de uma aguda consciência das finalidades da educação e da prática docente; e, ainda, dotando-os de uma formação teórico-científica, potente, capaz de emancipá-los. Contribuindo desse modo com o processo de formação omnilateral dos estudantes.
\end{abstract}

Palavras-chave: Didática. Pedagogia. Pedagogia histórico-crítica.

Abstract: The article aims to analyze the movement of anti-hegemonic proposals, notably, in the 1980s, in the context of the movement of critical didactics and their epistemological repercussions in the field of pedagogy and didactics. To do so, we examined some of the most significant productions in the field of didactics, which presuppose the dialectical method as a method of investigation. In the theoretical-methodological treatise we assumed the understanding of pedagogy being the science of and for the educational practice and Didactics, the theory of teaching in its entirety and in its movement. At the same time, we opted for Marx's SOCIAL BEING theory and its expressions in historical-critical pedagogy. The results of the study indicate that the critical didactic movement was not only an alternative to the official pedagogy, marked by the pedagogical technicality, but an opposition to the systematization of pedagogical guidelines that makes a rigorous criticism to the 
bourgeois perspective of school, at the same time that they struggle for the democratization of public schools, privileged space of systematized knowledge, historically advanced and systematized contents, for the professional valorization of teachers and their intellectual autonomy starting on the development of an acute awareness of the purposes of education and teaching practice; and, still, endowing them with a theoretical-scientific training, powerful, capable of emancipating them. Thus contributing to the students' omnilateral training process.

Keywords: Pedagogy. Didactic. Historical-critical pedagogy.

Resumen: El artículo tiene como objetivo analizar el movimiento de las proposiciones contrahegemónicas, notablemente en la década de 1980, en el contexto del movimiento didáctico crítico y sus repercusiones epistemológicas en el campo de la pedagogía y la didáctica. Para tal, examinamos algunas de las producciones más expresivas en el campo de la didáctica que asumen el método dialéctico como método de investigación. En el enfoque teórico-metodológico, suponemos que pedagogía es la ciencia de y para la práctica educativa y Didáctica, la teoría de la enseñanza en su totalidad y en su movimiento. Al mismo tiempo, eligimos la teoría SOCIAL SER de Marx y sus expresiones en la pedagogía histórico-crítica. Los resultados del estudio indican que el movimiento didáctico crítico no era solo una alternativa a la pedagogía oficial, marcada por el tecnicismo pedagógico, pero se opuso a la sistematización de pautas pedagógicas que hacen una crítica rigurosa de la perspectiva burguesa de la escuela, al mismo tiempo que luchan por la democratización de la escuela pública, espacio privilegiado de conocimiento sistematizado, de los contenido históricamente desarrollados y sistematizado, por la valoración profesional de los docentes y su autonomía intelectual a partir del desarrollo de una aguda conciencia de los propósitos de la educación y la práctica docente; y, así, dotarlos de formación teórico-científica, poderoso, capaz de emanciparlos. Contribuyendo así al proceso de formación omnilateral de los estudiantes.

Palabras clave: Pedagogía. Didáctica. Pedagogía histórico-crítica.

\section{Considerações Iniciais}

O artigo tem por objetivo analisar as proposições contra-hegemônicas, notadamente, nos anos de 1980, no contexto do movimento da didática crítica e suas repercussões epistemológicas no campo da pedagogia e da didática. No estudo, no que concerne aos fundamentos teórico-metodológicos, assumimos o materialismo histórico-dialético de Marx e Engels, por sua potência heurística, uma vez que nos ajuda a compreender como o real é produzido, como podemos conhecer os problemas concretos desta realidade, e, em especial, por que nos aponta a direção e as formas de superação e transformação dos desafios com os quais nos defrontamos.

No período de 29 de outubro a 12 de novembro do ano 2020, acontecerá o XX Encontro Nacional de Didática e Práticas de Ensino (ENDIPE) por meio virtual em função do distanciamento social, recomendado pela Organização Mundial da Saúde (OMS) e pelas autoridades políticas e sanitárias face a pandemia da SARS-CoV-2. Desde o I Seminário da Didática em questão, realizado na PUC, em 1982, são quase quatro décadas de permanentes 
estudos, pesquisas e lutas coletivas que os educadores brasileiros travam com o objetivo de, não apenas, compreender os problemas concretos da educação, e, da escola pública brasileira, mas simultaneamente, agir no seu interior com vistas a colocá-la a serviço da transformação social. Contudo levando em conta o que acontece hoje no Brasil, um governo civil-militar, de perspectiva ultraneoliberal, com viés fundamentalista e irracionalista, os intelectuais estão novamente convocados a refletir sobre a educação pública brasileira e buscar alternativas, no dissenso qualificado, que se contraponha à essa política educacional oficial. E este artigo é uma tentativa de no plano ético e ídeo-político apontar para a radicalidade da justiça social, pela aguda consciência teórica da concretude de nossa contemporaneidade, necessária ao efetivo exercício da práxis educativa

$\mathrm{Na}$ década de 1980, o movimento da didática crítica brota das motivações e necessidades de se discutir os problemas educacionais, seus vínculos com o contexto político e econômico vivenciado pela sociedade brasileira, assim como o papel da didática na proposição de um ensino que partisse da prática social, de seus reais problemas e a ela retornasse com os instrumentos teóricos de uma consciência crítica capaz de colaborar com os processos de mudanças da realidade social. As proposições pedagógicas orientadas por esta finalidade foram ricas e diversas, constituindo-se no pensamento contra-hegemônico próprio dos anos 1980, por sua inspiração em uma concepção dialética de educação.

\section{Contexto histórico e teórico do surgimento das orientações pedagógicas contra- hegemônicas}

Para melhor compreensão das ideias didático-pedagógicas que marcaram o movimento da didática crítica um exercício de perspectiva histórica é necessário. O contexto de organização e mobilização do campo educacional, notadamente na década de 1980, se manifesta pela a exigência de reorientação da prática educativa, a partir de proposições contra-hegemônicas. Saviani (2007a, p. 400) assevera que:

[...] uma particularidade da década de 1980 foi precisamente a busca de teorias que não apenas se constituíssem como alternativas à pedagogia oficial, mas que a ela se contrapusessem. Eis o problema que emergiu naquele momento: a necessidade de construir pedagogias contrahegemônicas, isto é, que em lugar de servir aos interesses dominantes se articulassem com os interesses dominados.

Candau (1992, p. 10), ao se referir à gênese do movimento de revisão da didática no Brasil, destaca: 
[...] a década de oitenta representou uma verdadeira revolução do pensamento em Didática no país. Foi uma etapa de ruptura de paradigmas, de negação, de buscas, de reconstrução. Atrevo-me a afirmar que foi a década mais fecunda na produção intelectual brasileira sobre a prática pedagógica e seus determinantes.

As condições de surgimento do pensamento contra-hegemônico se deram, em termos, do seguinte modo: fracassadas as promessas do milagre brasileiro e diante de uma crise econômico-social, bem como da forte repressão exercida pelos militares, vivenciamos, no final da década de 1970 e por toda a década de 1980, um período no qual homens ativos, autores e produtores promovem intensas mobilizações do campo às cidades, com o objetivo de fomentar e criar as condições políticas necessárias ao soerguimento da sociedade civil organizada, ao mesmo tempo em que combatem a permanência do regime militar.

As rearticulações da União Nacional dos Estudantes (UNE), em 1979, a Ordem dos Advogados do Brasil (OAB), as entidades de jornalistas, os intelectuais e a Igreja progressista ampliam a onda de reivindicações pela redemocratização, levando a burguesia a apostar na via democrática, uma vez que objetivava abandonar os parceiros indesejáveis do comando do Estado. É assim que, pela via do Colégio Eleitoral, elegem-se Tancredo Neves e José Sarney, pondo fim ao regime militar. As principais conquistas na luta pela democratização da sociedade brasileira, efetivamente, expressam-se no fim da censura à imprensa, na extinção do Ato Institucional no 5 (AI-5), na anistia política, 1979, e nas eleições diretas para governador, 1982.

Os cursos de Pós-graduação, surgidos em diversas áreas do saber, no início da década de 1970, com o objetivo de selecionar e hierarquizar elites de pesquisadores e professores, serviram para fortalecer uma concepção crítica de educação. Esse tipo de ensino oferecia melhores condições de trabalho, fomentando a realização de uma reflexão sistemática carente nos primeiros níveis de ensino. Começa-se a perceber que a comunidade acadêmica, já nos anos 1970, reorganiza-se no interior da sociedade civil a partir do momento que os debates internos anuais da Sociedade Brasileira para o Progresso da Ciência (SBPC) passaram a encampar a discussão do sentido propriamente político da produção científica.

No processo de redemocratização em que se tornara insustentável a permanência do regime militar, foi criada uma entidade não corporativa que se reivindicava herdeira da luta dos educadores progressistas em defesa do ensino público, gratuito, obrigatório, universal, laico e de boa qualidade: a Associação Nacional de Educação (Ande), em 1979, como também, em 1977, a Associação Nacional de Pós-graduação e Pesquisa em Educação (Anped), com a missão de retomar, em esfera nacional e no âmbito da sociedade civil, um 
crescente espaço de discussões, produção e socialização teórica no campo educacional. Em Campinas, cria-se, no ano de 1979, o Centro de Estudos, Educação e Sociedade (Cedes).

Assim, num esforço conjunto dessas três entidades é que, no início da década de 1980, realizam-se as Conferências Brasileiras de Educação (CBEs); sendo a primeira em São Paulo, 1980, a segunda em Belo Horizonte, 1982, e a terceira em Niterói, em 1984, seguidas das de 1986, 1988 e 1991. As temáticas centrais das CBEs, indicavam, respectivamente, os rumos e as preocupações dos educadores brasileiros: A política educacional; Educação: perspectiva na democratização da sociedade; Da crítica às propostas de ação; Educação e constituinte; A Lei de Diretrizes e Bases da Educação Nacional.

Saviani (2007) observa que a organização dos educadores na década de 1980 pode ser caracterizada por meio de dois vetores distintos: o primeiro era marcado pela preocupação com o significado social e político da educação, do qual decorre a busca de uma escola pública de qualidade, aberta a toda a população e direcionada precipuamente para as necessidades da maioria: a classe trabalhadora; o segundo, pautado pela preocupação com o aspecto econômico corporativo e, por isso mesmo, de caráter reivindicativo, manifestando-se de modo mais orgânicos pelas greves que eclodiram no final dos anos 1970 e se repetiram em ritmo, frequência e duração crescentes ao longo da década de 1980.

No campo teórico-político, a preocupação com a escola pública de qualidade, dirigida particularmente para as classes trabalhadoras foi aos poucos, ao longo das CBEs, ganhando consistência, permitindo-se ir além do diagnóstico e da denúncia. Nesse sentido, a respeito da I CBE, Saviani (2007, p. 403) entende que:

[...] agora, em lugar da denúncia, a preocupação principal passa a girar em torno da busca de propostas alternativas para encaminhar os problemas da educação brasileira [...]. Essa nova tendência irá acentuar-se progressivamente nas CBEs seguintes [...]. Preocupada com as novas propostas pedagógicas, essa fase abriu espaço para a emergência de concepções contra-hegemônicas.

Saviani (2006) destaca como marco na década de 1980, na superação dos limites da crítica na compreensão da relação escola e sociedade capitalista, as sistematizações de Frigotto (1989). Após reconstituir a lógica interna e a gênese histórica da teoria do capital humano, o autor mostra que a escola não é produtiva a serviço dos indivíduos indistintamente, no seio de uma sociedade sem antagonismos, como supunham os adeptos da teoria do capital humano. Também não é ela produtiva a serviço exclusivo do capital como pretendiam os críticos (reprodutivistas) da referida teoria. E nem mesmo é ela simplesmente improdutiva como pretenderam os críticos da crítica à teoria do capital humano. O que Frigotto (1989) 
procura fazer é captar a existência do vínculo entre escola e trabalho, porém percebendo, ao mesmo tempo, que não se trata de um vínculo direto e imediato, mas indireto e mediato. A expressão "produtividade da escola improdutiva", que dá título ao livro de Frigotto, quer sintetizar essa tese. A escola (imediatamente) improdutiva é (mediatamente) produtiva.

As proposições contra-hegemônicas são entendidas por Saviani (2008a, p. 170) como aquelas "orientações que não apenas não conseguiram tornar-se (sic) dominantes, mas que buscam intencional e sistematicamente colocar a educação a serviço das forças que lutam para transformar a ordem vigente visando a instaurar uma nova forma de sociedade". Para o pensador, no entanto, as ideias pedagógicas contra-hegemônicas apresentavam características de ambiguidades e heterogeneidade ao comportar desde os liberais progressistas até os radicais anarquistas, passando pela concepção libertadora e por uma preocupação com a fundamentação marxista. Entende que, por essas características, pensando com Snyders (apud SAVIANI, 2007a, p. 412), a denominação que poderia abranger o conjunto das propostas contra-hegemônicas, seria a expressão pedagogias de esquerda e não pedagogia marxista ou revolucionária: uma pedagogia de esquerda, com toda a vagueza "que o termo comporta, e também com todas as esperanças de entendimento, de união de que o termo está carregado".

O autor, grosso modo, organiza as propostas em duas modalidades: uma centrada no saber do povo e na autonomia de suas organizações, preconizava uma educação autônoma e, até certo ponto, à margem da estrutura escolar e, quando dirigida às escolas propriamente ditas, buscava transformá-las em espaços de expressão das ideias populares de exercício da autonomia popular; outra, pautada pela centralidade da educação escolar, valorizava o acesso das camadas populares ao conhecimento sistematizado.

A primeira tendência fundamentava-se na concepção libertadora pensada, elaborada e difundida por Paulo Freire, estando próxima à Igreja em afinidade com a teologia da libertação e, secundariamente, nas ideias libertárias constitutivas da tradição anarquista. Em termos da conjuntura política, a referência principal era dada pelo Partido dos Trabalhadores (PT). Sua relação com a educação pública era marcada por ambiguidades, introduzindo-se a distinção entre público e estatal.

A segunda tendência, que teve a Revista da Ande como um canal de expressão e comunicação aglutinou representantes cuja orientação teórica predominante se inspirava no marxismo. Saviani chama atenção para o fato de que este deve ser entendido, no entanto, com diferentes aproximações: uns mantinham como referência a visão liberal, interpretando o marxismo apenas pelo ângulo da crítica às desigualdades sociais e da busca de igualdade de acesso e permanência nas escolas organizadas com o mesmo padrão de qualidade; outros se 
empenhavam em compreender os fundamentos do materialismo histórico, buscando articular a educação com uma concepção que se contrapunha à visão liberal.

Em termos teórico-pedagógicos, surgiram tentativas de elaborar propostas suscetíveis de orientar a prática educativa numa perspectiva de transformação social. As duas primeiras serão abordadas panoramicamente e as demais serão analisadas com mais vagar, por se voltarem de modo mais direto à educação escolar, a saber: a) pedagogias da educação popular; b) pedagogias da prática; c) pedagogia crítico-social dos conteúdos; d) pedagogia histórico-crítica.

No interior da primeira tendência, as "propostas inspiradas na concepção libertadora geralmente se assumiam no âmbito da expressão 'educação popular' e advogavam a organização, no seio dos movimentos populares, de uma educação do povo e pelo povo, para o povo e com o povo" (SAVIANI, 2007a, p. 413). Tal posicionamento se contrapunha diretamente "àquela dominante caracterizada como da elite e pela elite, para o povo, mas contra o povo". Ainda "no âmbito da primeira tendência, surgiram propostas de inspiração libertária, portanto em consonância com os princípios anarquistas. Estas, geralmente se assumiam como 'pedagogia da prática' e, diferentemente dos adeptos da visão libertadora, trabalhavam com o conceito de classe" (SAVIANI, 2007a, p. 414).

O seu principal expoente, Santos (apud SAVIANI, 2007a, p. 414), adverte que “o saber 'gerado na prática social' é relegado pela escola, mas é exatamente esse saber que 'deve ser valorizado e constituir a matéria-prima do processo de ensino"”. Num primeiro momento, esse saber se manifesta de forma imediata como prática individual. "Cabe, pois, num segundo momento, ultrapassar essa aparência e captar sua natureza própria como 'síntese de múltiplas determinações' que, 'em última instância, é social, é de classe"” (SANTOS apud SAVIANI, 2007a, p. 414). "Essa mesma perspectiva foi adotada também por Miguel Gonzalez Arroyo e por Maurício Tragtenberg”, afirma Saviani (2007a, p. 415).

\section{Pedagogia crítico-social dos conteúdos}

No interior da segunda tendência, situa-se a proposta designada pedagogia críticosocial dos conteúdos, formulada e apresentada por Libâneo (1985), no livro Democratização da escola pública, que reuniu artigos publicados entre 1982 e 1984. Nele, o autor afirma que:

[...] a democratização da escola pública, portanto, deve ser entendida aqui como ampliação das oportunidades educacionais, difusão de conhecimentos e sua reelaboração crítica, aprimoramento da prática educativa escolar 
visando à elevação cultural e científica das camadas populares [...]. (LIBÂNEO, 1985, p. 12).

Para o pensador, desse modo, a escola contribuiria simultaneamente com as classes populares satisfazendo às necessidades imediatas com sua melhoria de vida e inserindo-as num projeto coletivo de mudança social; contudo, "é imperioso buscar uma pedagogia e uma didática que, partindo da compreensão da educação na prática social histórica e concreta, ajudem os professores no trabalho docente com as camadas populares" (LIBÂNEO, 1985, p. 12).

Assim mesmo, o autor se questiona a respeito do por que da pedagogia-crítico-social dos conteúdos, ao mesmo tempo em que responde no que consiste esse modo pedagógico de pensar explicitando:

[...] trata-se de uma pedagogia que leva em conta os determinantes sociais e que propicia a crítica dos mecanismos e imposições resultantes da organização da sociedade em classes sociais antagônicas; [...] que vai buscar, no interior da escola, respostas pedagógico-didáticas que permitam o exercício dessa crítica, a partir das próprias determinações sociais das situações pedagógicas concretas. (LIBÂNEO, 1985, p. 12).

Ao referir-se à pedagogia crítico-social dos conteúdos Saviani (2007a) comenta que:

[...] a denominação "pedagogia crítico-social dos conteúdos" inspira-se diretamente em Snyders, que sustenta a "primazia dos conteúdos" como critério para distinguir as pedagogias entre si e, mais especificamente, para distinguir uma pedagogia progressista ou de esquerda de uma pedagogia conservadora, reacionária ou fascista. (SAVIANI, 2007a, p. 416).

Tendo como principal fonte teórica o pensador Snyders, autor marxista, Libâneo sinaliza para o horizonte teórico do marxismo. Com efeito, as aproximações deste último com o materialismo histórico-dialético aconteceram de modo mais efetivo na tese de doutoramento denominada Fundamentos teóricos e práticos do trabalho docente: estudo introdutório sobre pedagogia e didática, defendida em 1990 na Pontifícia Universidade Católica de São Paulo (PUC-SP).

Ao abordar o trabalho docente da perspectiva didático-pedagógica, o autor estabeleceu interlocução com o movimento da didática crítica que se desenvolveu ao longo da mesma década de 1980, cujos principais canais de comunicação são apresentados pelos seminários denominados A Didática em Questão e pelos Encontros Nacionais de Didática e Prática de Ensino (Endipes). 


\section{Pedagogia histórico-crítica}

A síntese apurada das ideias contra-hegemônicas que constituíram a denominada pedagogia histórico-crítica, segundo Saviani (2007a), remonta às discussões travadas na primeira turma de Doutorado em Educação da PUC-SP de 1979. A primeira tentativa de sistematização deu-se no artigo "Escola e democracia: para além da teoria da curvatura da vara”, publicado na Revista da Ande, em 1982, que veio a integrar o livro Escola $e$ democracia, editado em 1983.

Para o autor, a pedagogia histórico-crítica, numa síntese apertada, "é tributária da concepção dialética, especificamente na versão do materialismo histórico, tendo fortes afinidades no que se refere às suas bases psicológicas, com a psicologia histórico-cultural desenvolvida pela Escola de Vigotski” (SAVIANI, 2007a, p. 419). Ao definir e explicitar sua concepção de educação, afirma que esta "é entendida como o ato de produzir, direta e intencionalmente, em cada indivíduo singular, a humanidade que é produzida histórica e coletivamente pelo conjunto dos homens" (SAVIANI, 2007a, p. 419-420).

Desse modo, a educação é entendida como mediação no seio da prática social global. A prática social coloca-se, assim, como o ponto de partida e de chegada da prática educativa. Daí decorre um método pedagógico que parte da prática social, na qual professor e aluno se encontram igualmente inseridos, ocupando, porém, posições distintas - condição para que travem uma relação fecunda na compreensão e no encaminhamento da solução dos problemas postos pela prática social. Aos momentos intermediários do método, cabe identificar as questões suscitadas pela prática social - problematização -; dispor os instrumentos teóricos e práticos para a sua compreensão e solução - instrumentação -; e viabilizar sua incorporação como elementos integrantes da própria vida dos alunos - catarse.

A pedagogia histórico-crítica tem seus fundamentos históricos, ontológicos e gnosiológicos nas trilhas abertas pelas agudas investigações desenvolvidas por Marx na formulação da teoria do ser social. Na qual investigou as condições históricas de produção da existência humana que resultam na forma da sociedade contemporânea dominada pelo capital. É, pois, no espírito de suas investigações que essa proposta pedagógica se inspira.

Norteado pelo referencial teórico metodológico marxiano, Saviani (2008a, 2008b, 2005b, 2007a), desenvolveu também estudos sobre Política Educacional, Filosofia da Educação e Teoria Didática. Com a obra Escola e democracia, Saviani (2008b) vem promovendo significativas mudanças no pensamento pedagógico nacional e, inegavelmente, no pensamento pedagógico latino-americano. 
Nessa obra, Saviani (2008b) evidencia e explicita, a partir de uma análise na qual a luta de classes mostra-se presente objetivamente na realidade e, em particular, na trama relativa aos fenômenos educacionais, o caráter ingênuo e reacionário das teorias pedagógicas liberais, denominando-as não críticas, assim como o limite das teorias crítico-reprodutivistas quando afirmam que a função própria da educação é a reprodução da sociedade, podendo assim dar um passo decisivo na superação delas. Ao propor uma pedagogia revolucionária centrada na igualdade essencial entre os homens, igualdade essa em termos reais e não apenas formais, "busca converter-se, articulando-se com as forças emergentes da sociedade, em instrumento a serviço da instauração de uma sociedade igualitária" (SAVIANI, 2008b, p. 52) e considera a transmissão, difusão de conteúdos vivos e atualizados, uma das tarefas primordiais do processo educativo em geral e da escola em particular.

Como uma pedagogia revolucionária, percebe-se condicionada, não entendendo a educação como determinante principal das transformações sociais, mas reconhecendo ser ela elemento secundário e determinado; no entanto, combate radicalmente a ideia de que a educação é determinada unidirecionalmente pela estrutura social e compreende que, mesmo como elemento determinado, a educação não deixa de influenciar o elemento determinante, relacionando-se dialeticamente com a sociedade, numa interação marcada por avanços e recuos e, por vezes, até mesmo decisiva na transformação das sociedades. É esse o entendimento do pensador quando afirma:

[...] pedagogia crítica implica a clareza dos determinantes sociais da educação, a compreensão do grau em que as contradições da sociedade marcam a educação e, consequentemente, como é preciso se posicionar diante dessas contradições e de desenredar a educação das visões ambíguas, para perceber claramente qual é a direção que cabe imprimir à questão educacional. (SAVIANI, 2005b, p. 100).

Sobre a especificidade da escola, Saviani (2005b, p. 98) esclarece que esta tem uma “função especificamente educativa, propriamente pedagógica, ligada à questão do conhecimento; é preciso, pois, resgatar a importância da escola e reorganizar o trabalho educativo, levando em conta o problema do saber sistematizado, a partir do qual se define a especificidade da educação escolar".

\section{O movimento da didática crítica: contexto, motivações e questões}

O objetivo aqui não é realizar o estudo do movimento de constituição da didática crítica no Brasil, mas sim de identificar aquelas proposições pedagógico-didáticas de orientações contra-hegemônicas, em particular, daquelas que se manifestam a partir do 
materialismo histórico-dialético. Com efeito, por imposição metodológica, esse caminho não poderá ser trilhado sem que nos voltemos, panoramicamente, para a história daquele movimento, por se tratar de questões que se colocam de modo inerente aos debates, aos estudos e às pesquisas do conhecimento didático.

De modo simultâneo aos debates sobre educação escolar na década 1980, concentram-se os esforços, os estudos e as reflexões sobre o objeto de estudo da didática, sua função no ensino e o papel da escola na ordem burguesa. Dois momentos iniciais desse debate são considerados ricos nesse sentido: o simpósio sobre o discurso pedagógico ocorrido na XXVII Reunião Anual da SBPC, em Belo Horizonte, 1976; e o 1ํ Seminário A Didática em Questão, em novembro de 1982.

Ao discutirem a prática de ensino de didática no Brasil, Oliveira e André (1997, p. 10) assim se posicionam:

[...] a partir de então o saber didático caracteriza-se por discutir suas limitações epistemológicas, às quais se juntam as críticas ao seu caráter ideológico e à sua funcionalidade em relação ao papel do ensino e da escola ligado à reprodução das relações sociais de produção e, consequentemente, à manutenção do sistema socioeconômico e político brasileiro vigente.

É nesse espaço que vários pesquisadores da didática se colocam no desafio da superação de uma didática instrumental à construção de uma didática fundamental, ancorada em alguns princípios básicos que são apresentados por Candau (2000a, p. 23-24), "multidimensionalidade do processo ensino-aprendizagem; análise da problemática educacional concreta; contextualização da prática pedagógica; explicitação e análise dos pressupostos; experiências concretas [...] [e] a relação teoria-prática".

Candau (1997, p. 74) entende que a contraposição entre instrumental e fundamental indicaria duas abordagens claramente distintas sobre a natureza da didática, presentes na teoria e na prática pedagógicas. A autora observa que, para as referidas perspectivas, a didática é concebida do seguinte modo: "A primeira concebe a Didática como um conjunto de procedimentos e técnicas [...]. É a operacionalidade do processo que constitui a preocupação" (CANDAU, 1997, p. 74), ao passo que a segunda:

[...] parte da análise da relação escola-sociedade e articula as abordagens da educação com os diferentes projetos político-sociais, situando-se na perspectiva da construção de uma sociedade democrática de caráter inclusivo e radical. Procura penetrar na problemática educacional assim como nas práticas pedagógicas, identificando seus diferentes determinantes. (CANDAU, 1997, p. 74). 
O movimento iniciado com a didática em questão encontrou na didática fundamental sua forma mais expressiva. Com efeito, o desafio posto a todos os educadores, das distintas posições no tocante ao objeto de estudo da didática, vinculava-se à superação da simples denúncia do caráter instrumental da didática. Martins, P. (2008, p. 590) afirma que "ao longo da década de oitenta, as produções teóricas dos educadores expressam tentativas de dar conta dessa nova situação". Sobre esse momento, identifica que "o grande desafio [...]era ultrapassar o nível da crítica apontando alternativas concretas para o ensino de Didática mais articulado com a realidade das escolas de Ensino Fundamental e Médio e com os interesses e necessidades práticas da maioria da população".

A busca da reconstrução da didática - entendida nos termos explicitados por Oliveira (1992), de seu objeto de estudo, de sua especificidade, é caracterizada pela existência de manifestações teóricas distintas. Com efeito, todas se situando no interior de uma visão crítica de educação. Martins, P. (2008, p. 590), discutindo a história recente da didática no Brasil, identifica esses grupos ao afirmar que, "por um lado, encontram-se grupos que discutem a importância de formar uma consciência crítica nos professores para que estes coloquem em prática as formas mais críticas de ensino, articuladas aos interesses e necessidades práticas das camadas populares" Por outro lado, "encontram-se grupos mais radicais, voltados para a alteração dos próprios processos de produção do conhecimento; das relações sociais" (MARTINS P., 2008, p. 592). Nessa direção, a autora afirma que a obra A pedagogia dos conflitos sociais, de Oder José dos Santos é a base teórica de seus estudos na formulação das proposições da "Sistematização coletiva do conhecimento" (MARTINS P., 2008, p. 592). Aqui é intensificada a ideia de que o movimento das pedagogias contra hegemônicas se constitui e é, ao mesmo tempo, constituinte dos amplos esforços de construção de uma didática crítica.

Oliveira (2000, p. 164), na mesa de 20 anos de Endipes, caracterizando a produção no campo da didática, faz uma releitura de sua análise sobre os cinco primeiros Endipes, destacando que, "entretanto, a releitura desse processo, a partir da indagação sobre existência de consenso no dissenso e de dissenso no consenso, permite um novo entendimento". Nessa releitura, a autora constata que, para além dos diferentes modos de entender o objeto de estudo das áreas, o que existe na verdade é um grande consenso. Essa maneira de ver é evidenciada na seguinte afirmação:

[...] ele se refere à luta em defesa da legitimidade do saber didáticopedagógico, enquanto constituindo um campo de conhecimento e enquanto conteúdo do currículo da formação do educador, no contexto da luta pela 
especificidade e importância do papel dos processos da educação e do ensino, no movimento de recuperação e democratização da escola pública, e na transformação social. (OLIVEIRA, 2000, p. 164-165).

Sobre o dissenso que marca o debate do referido consenso, Oliveira (2000, p. 165) afirma que os estudos apontam para posições diferentes em torno de duas grandes correntes, as quais "[...] se diferenciam segundo o maior ou menor grau de importância que atribuem ao saber sistematizado ou ao saber da prática no atendimento àquelas finalidades". Finalidades que se traduzem na defesa e valorização da escola pública e na contribuição dos processos educativos na transformação da ordem vigente. Com efeito, esse dissenso encontra no V Endipe sua superação com a "redefinição do saber teórico-prático das áreas, que centrariam suas concepções e práticas formativas no trabalho docente, no contexto das discussões acerca da organização do processo de trabalho na escola capitalista” (OLIVEIRA, 2000, p. 166).

Oliveira (2000) observa que essa redefinição representava no contexto social mais amplo a possibilidade de uma formulação mais consolidada de uma perspectiva radical concernente ao saber didático com bases teóricas assentadas no materialismo históricodialético, como também a legitimidade científico-acadêmica de novos agentes no processo de construção desse saber.

\section{Da produção científica no campo da didática a partir do método dialético}

No conjunto dessas pesquisas sobre didática, consideramos cinco como expressivas à problemática deste estudo. A primeira das pesquisas situa-se nos marcos iniciais da construção didática. Trata-se da tese de Doutorado Libâneo (1990), intitulada Fundamentos teóricos e práticos do trabalho docente: estudo introdutório sobre pedagogia e didática. Ao discutir o trabalho docente no estudo sobre pedagogia e didática, Libâneo (1990, p. 19), assim apresenta o objetivo de sua pesquisa:

[...] investigar a natureza e a dinâmica do trabalho docente no seu desenvolvimento histórico; esclarecer seu caráter de práxis, enquanto atividade produtiva não-material conectada com a atividade sócio-política; investigar seus fundamentos teórico-práticos, explicitados na Pedagogia dialética de base histórico-dialética e, simultaneamente, restabelecer os vínculos teóricos entre Pedagogia e Didática, nos seus aspectos lógico e histórico; indicar aos docentes subsídios de fundamentação teórica e sistemática do processo de ensino na escola.

Nesse estudo, o autor evidencia sua opção teórico-metodológica, quando registra: 
[...] pretendemos, pois, enfocar de um ponto de vista materialista históricodialético, a natureza, o processo, a estrutura interna (relações) e os elementos constitutivos da docência - e sua tarefa, o ensino - tendo como referência a teoria pedagógica na sua relação dialética com a prática educativa. (LIBÂNEO, 1990, p. 6).

Libâneo (1990), ancorado em Snyders, Suchodolski, Schmied-Kowarzik, compreende que a pedagogia é ciência que investiga finalidades e meios do processo educativo no seio da práxis histórico-social. É ciência teórica e prática que investiga os fatos que contribuem para a formação dos indivíduos e os processos dessa formação em seu desenvolvimento histórico-social, tendo em vista a orientação racional da educação humana. Para o autor, o objeto da pedagogia é a atividade educativa como acontecimento real historicamente mutável; contudo, destaca que os âmbitos dos estudos pedagógicos são extensivos a toda prática educacional intencionada e aos meios educativos correspondentes, não se restringindo, dessa maneira, à educação escolar.

Ao evidenciar sua concepção de ciência, mais uma vez o pensador se vale de autores marxistas para observar que parte "de uma acepção ampliada do termo ciência, seja como processo de investigação dos fatos conforme um método geral, o método dialético" (LIBÂNEO, 1990, p. 248). Explicita o conceito de ciência no âmbito do materialismo histórico-dialético, ao afirmar que a "ciência é uma atividade humana de produção espiritual em unidade e interação com a práxis cujo objetivo é a produção do saber mediante métodos sistemáticos". (LIBÂNEO, 1990, p. 248) Desse modo, o conhecimento é considerado científico quando se manifesta pela "unidade dialética entre um sistema de conceitos, categorias e leis, um método de conhecimento de um objeto ou aspecto da realidade, e uma ligação indissolúvel com a prática, esta como fator histórico-social determinante dele" (KEDROV apud LIBÂNEO, 1990, p. 248).

E é no âmbito dessa compreensão que se colocam a pedagogia como ciência da e para a prática educativa e a didática como teoria do ensino. Libâneo (1990), no entanto, entende que a didática tem sua fundamentação na teoria pedagógica, pois há um domínio da realidade que lhe é próprio, a educação, e o seu foco de interesse é o educativo, cabendo apenas a essa ciência fornecer respostas às questões e aos processos que são próprios da formação humana. $\mathrm{O}$ autor, contudo, chama a atenção para o caráter histórico do objeto da pedagogia e da didática ao asseverar que: "a Didática, tal como a pedagogia, ao construir o ensino como seu objeto e ao definir sua função de transmissão e assimilação da experiência humana generalizada, somente pode fazê-lo 'construindo-o', 'formando-o' pois é historicamente mutável” (LIBÂNEO, 1990, p. 408). 
No desenvolvimento histórico, a tarefa da didática "sempre esteve ligada à determinação de conteúdos de ensino, métodos de aquisição de conhecimentos e à investigação de leis objetivas e regularidades desse processo" (LIBÂNEO, 1990, p. 408); todavia, chama atenção para o fato de que "o caráter histórico desta tarefa requer que se cumpra de modo a vincular-se a exigências e necessidades concretas do desenvolvimento social" (LIBÂNEO, 1990, p. 408). O autor posiciona-se sobre o objeto de estudo da didática explicando que:

[...] numa primeira aproximação do objeto da Didática, podemos dizer que é o estudo do ensino para conhecer às leis objetivas e as condições de sua manifestação, pela investigação dos fatores reais condicionantes das relações entre docência e aprendizagem, de modo que a didática possa constituir-se de um lado, em teoria que embasa a mediação escolar de objetivos, conteúdos de ensino e, de outro, em orientação segura para a direção da prática docente. (LIBÂNEO, 1990, p. 408).

Nesse sentido, entende Libâneo (1990) que o processo didático para a teoria do ensino de inspiração dialética é direção e organização do processo de assimilação consciente e ativa de conhecimentos pelo aluno. Aqui, para o autor, está sua condição básica: a unidade dialética de duas dimensões distintas, o ensino e a aprendizagem, a docência e o estudo. Essa unidade se efetiva na medida em que a docência consiste em dirigir, organizar, incentivar, suscitar a atividade cognitiva do aluno mediante conteúdos e formas de trabalho pedagógico, com vistas ao desenvolvimento do pensamento autônomo, criativo e crítico.

A lógica do trabalho didático na teoria do ensino de base dialética está em que as tarefas que se propõem aos alunos não aparecem como algo estático e externo, "mas como um movimento que capta a mente dos alunos e no qual os fatos isolados e noções concretas se manifestem em vínculo indissolúvel com a síntese e os conceitos que, unidos a habilidades e hábitos, levem à sua aplicação na vida" (LIBÂNEO, 1990, p. 491).

Saviani (2007) entende que, por esse caminho, Libâneo (1990) diferenciou-se, de certo modo, do grupo daqueles que, embora levando em consideração a referência do marxismo, não chegam a ultrapassar o horizonte liberal no encaminhamento das questões educacionais. Saviani esclarece que esse grupo, nos anos 1990, aderira às reformas educativas alcunhadas de neoliberais, assumindo postos no aparelho governamental em nível federal, estadual e municipal, de modo geral integrando ou aproximando-se do Partido da Social Democracia Brasileira (PSDB). 
As proposições de Libâneo (1990), a partir daí, ganham expressividade, notadamente no meio acadêmico, e passam a orientar os planos de ensino dos professores de didática, não apenas nos cursos de formação de professores em nível médio, mas também nas licenciaturas.

A segunda pesquisa refere-se ao trabalho de Wachowicz (1991), O método dialético na Didática. Saviani, no prefácio de WACHOWICZ (1991, p. 8), afirma:

[...] à medida que a concepção dialética de educação foi sendo formulada e difundida é compreensível que se indague sobre as implicações desse fato na didática. Nesse contexto vem tomando corpo nos últimos anos no nosso País uma corrente de educadores empenhados em abordar a didática a luz do pensamento dialético.

Wachowicz (1991, p. 11) está preocupada em tomar a aula como principal objeto da didática, pois ela parte de entendimento da "certeza de que o que se faz e como se faz no ensino tem muito mais importância do que o que se diz". A autora coloca o método de trabalho do professor em destaque. No entanto, pelo estudo da concepção dialética de educação e de seu método, entende que "a pedagogia vem então trabalhar sobre a questão de como se realiza a apropriação do saber pela sociedade, e a didática vem trabalhar sobre a questão do método pelo qual se realiza a apropriação do saber pelas pessoas" (WACHOWICZ, 1991, p. 51).

A pensadora destaca que propõe não um método didático geral, mas um método de pensamento, de uma lógica dialética que supera a lógica formal e indica etapas para que o pensamento se aproprie da realidade, traduzindo-se no movimento prática-teoria-prática. Assim, explicita seu entendimento observando que "quando tratamos de um método didático não o entendemos como um método geral, mas decorrente de um método de pensamento" (WACHOWICZ, 1991, p. 94).

A terceira refere-se aos estudos acumulados por Oliveira (1992), com base especialmente na obra A reconstrução da didática: elementos teóricos metodológicos. A proposta apresentada pela autora traz, já no título, de forma clara, a intenção a que ela se propõe:

[...] o objetivo deste estudo é sugerir elementos teórico-metodológicos para se reconstruir a Didática, com base numa concepção dialético-materialista do ensino e numa direção de continuidade e ruptura com os trabalhos que vêm sendo desenvolvidos na área, no cerne do movimento de revisão crítica da Didática no Brasil, nos últimos dez anos. (OLIVEIRA, 1992, p. 13).

Por ser a intencionalidade do estudo direcionada para as contribuições da construção da didática, a autora, ao discutir a especificidade e a identidade em termos do objeto de estudo 
e conteúdo da didática, se posiciona: "a Didática que estou propondo resgata os princípios que permeiam o caráter crítico da Didática atual, dentro de uma nova estrutura de totalidade" (OLIVEIRA, 1992, p. 29).

A autora destaca ainda uma nova compreensão da estrutura da categoria de totalidade, para a qual os conteúdos dessa nova didática se expressam nos núcleos de discussão: dimensão histórica, dimensão antropológica, dimensão ideológica e dimensão epistemológica. O aprofundamento do entendimento dessas dimensões se fez mediante a busca de elementos teórico-metodológicos que:

[...] se referem a categorias ou propriedades essenciais da realidade do ensino, expressando a apreensão do movimento das relações no seu interior e, ao mesmo tempo, possibilitando o entendimento dos mecanismos de relações entre o ensino escolar, o sistema educacional e o sistema social mais amplo. (OLIVEIRA, 1991, p. 41).

Nessa perspectiva, Oliveira (1991, p. 41) discute a didática, seja como campo de conhecimento, seja como disciplina no currículo dos cursos de formação de educador "em seu caráter de conhecimento em processo contínuo de construção lógico-histórica sobre o ensino. Daí a expressão construção e reconstrução da Didática” (grifo do autor). Ainda para a autora, em seu termo reconstrução, implica a defesa de uma nova didática, de base dialéticomaterialista do ensino que se faz na "direção de concordância e ruptura simultâneas com os trabalhos que vêm sendo desenvolvidos, no cerne do movimento de revisão crítica da área, no Brasil, a partir de 1980" (OLIVEIRA, 1991, p. 41).

A nova didática, para Oliveira (1991), assenta-se na concepção de ensino como uma totalidade concreta. E, entendê-lo assim, para a autora, significa apreender o fenômeno do ensino em seu caráter antropológico de trabalho didático, produzido socialmente como práxis, articulado às bases materiais da sociedade que se pretende transformar e que tem a sala de aula como sua expressão molecular; desvincular esse ensino das abordagens positivistas e sistêmicas, das formas fragmentadas, de modelos formais e desconteudizados implica seu tratamento como uma realidade inteira em movimento, e que se sabe inexaurível ao conhecimento.

A quarta pesquisa constitui-se dos estudos apresentados por Pimenta (2001, 2005), no VII Endipe, Panorama atual da didática no quadro das Ciências da Educação: educação, pedagogia e didática, de 2001, como também a segunda parte do livro $O$ estágio na formação de professores: unidade teoria e prática? Parte II, práxis - ou da indissociabilidade entre 
teoria e prática e a atividade docente, de 2005, resultante de sua tese de livre-docência em didática.

No primeiro estudo, a autora tem como objetivo trazer para a discussão alguns aspectos sobre a especificidade da didática que, segundo ela, não têm sido suficientemente considerados entre os pesquisadores da pedagogia e da didática; no segundo, numa confluência com o anterior, a discussão pauta-se pela centralidade da unidade entre teoria e prática na formação de professores para as séries iniciais.

Ao referir-se à natureza do objeto da ciência da educação, Pimenta (2001, p. 58) observa a insuficiência dos métodos positivistas lógicos e aponta as possibilidades do método dialético, na medida em que entende que a "educação é uma ciência prática que tem por objeto de investigação a educação como prática social histórica [...]”. Por isso, para a autora, é um objeto inconcluso, que constitui o sujeito que investiga e é por ele constituído, não sendo, portanto, captado na sua integralidade, mas na sua dialeticidade: no seu movimento, nas suas diferentes manifestações como prática social, nas suas contradições, nas suas diferentes direções, usos e finalidades.

A tarefa da pedagogia dialética

[...] é, pois, proceder à análise situacional da educação para a elucidação de situações como sendo educativas (no sentido da humanização); a interpretação do sentido da educação como formação humana; a autoreflexão dialética sobre as possibilidades e limitações de enunciados pedagógicos da e para a prática educacional. (PIMENTA, 2001, p. 55).

Ainda nessa obra, Pimenta (2001) entende a didática como uma área de estudos da ciência da educação, pedagogia, e assim como esta tem um caráter prático, práxis. O objeto de estudo específico é a problemática do ensino em situação, na qual a aprendizagem é a intencionalidade almejada e seus sujeitos imediatamente envolvidos: professor, aluno e conhecimento são analisados nas suas determinações histórico-sociais. "O objeto de estudo da Didática não é nem o ensino, nem a aprendizagem; mas o ensino e sua intencionalidade é que a aprendizagem, tomados em situação" (PIMENTA, 2001, p. 63).

Ao definir, assim, o objeto da didática, a autora interroga-se: Mas como entendê-lo dialeticamente; como investigá-lo na direção de se identificar nele as possibilidades de contribuir com o processo de humanização dos homens? Ao mesmo tempo, diz que as respostas a esse questionamento não são simples nem prontas e acabadas. Elas constituem o próprio movimento histórico de construção e reconstrução da didática como área de conhecimento. 
Com efeito, Pimenta (2001) salienta que a didática, como área da pedagogia, contribui com as outras na formação de professores; como disciplina de curso, traduz-se em um programa de estudos do fenômeno processo ensino-aprendizagem com o objetivo de preparar os professores para a atividade sistemática de ensinar em uma dada situação histórico-social, inserindo-se nela com o objetivo de transformá-la a partir das necessidades aí identificadas para direcioná-las para o projeto de humanização. Para tal empreendimento, no entanto, Pimenta considera que devemos nos voltar para o existente, tomá-lo como referência para conhecer o seu modo de existir.

A última trata-se dos estudos de Freitas (1995), apresentados na obra Crítica da organização do trabalho pedagógico e da didática. Com posicionamento divergente das proposições da didática fundamental, da pedagogia histórico-crítica e da pedagogia dos conflitos sociais, o autor afirma que "esta proposta de trabalho foi elaborada para fazer frente à tentativa, frequente no campo da didática, de se criar, pela via da análise teórica, uma didática alternativa" (FREITAS, 1995, p. 12). Do ponto de vista do autor, a didática somente poderá superar seu caráter instrumental se analisada a partir das contradições da escola capitalista; contudo, ele entende que "para tal será necessário um esforço no sentido de construirmos um sistema de categorias que dê conta de tais contradições e abram possibilidades de superação" (FREITAS, 1995, p. 12). Sobre seu estudo, esclarece:

[...] o âmbito deste estudo pode ser circunscrito ao exame da avaliação/objetivos como uma das categorias centrais da didática, na escola capitalista [...]. A categoria avaliação objetivos será pensada de forma específica e de forma ampliada. Sempre se referirá tanto à avaliação/objetivos em nível de sala de aula, quanto ao nível da escola como instituição social [...] tanto em nível "didático" quanto em nível da organização da escola como um todo. (FREITAS, 1995, p. 12-13).

No estudo, Freitas (1995) apresenta preocupações epistemológicas e as faz a partir das teses do materialismo histórico-dialético. Com efeito, destaca a necessidade de não tomarmos isoladamente questões da produção do conhecimento desvinculadas do modo de produção da vida material dos homens:

[...] não se trata, pois, de tomar da análise marxista apenas seu "conteúdo metodológico" ou suas "categorias explicativas". Assumir uma abordagem marxista implica articular o método da análise da realidade, o sistema de categorias explicativas do modo de produção capitalista e sua superação [...]. (FREITAS, 1995, p. 142).

Ao tratarmos, mesmo que panoramicamente, das pesquisas significativas ao estudo e ao debate do objeto de estudo da didática, que assumem o método dialético como método de 
investigação, é importante destacar que estas são hoje pesquisas amplamente conhecidas pelos professores que lidam mais diretamente na universidade com a formação de professores e com a Didática.

\section{Considerações Finais}

O estudo analisa as concepções contra-hegemônicas de educação e suas repercussões no pensamento pedagógico-didático brasileiro. Para tanto identifica pesquisas expressivas no campo da didática que assumem o método dialético como método investigativo. Assumimos como referencial teórico a concepção materialista históricodialética de homem, de sociedade e de conhecimento e sua inspiração na educação, a pedagogia histórico-crítica.

O movimento da didática crítica é amplo e plural com orientações pedagógicas distintas, com suas aproximações e diferenças, com seus consensos e dissensos, mas todas com um ponto em comum: colocar a educação a serviço da transformação da ordem social capitalista.

São produções comprometidas com a defesa da democratização da escola pública, sendo esta considerada como espaço privilegiado de transmissão e apropriação do saber sistematizado pelos filhos das classes trabalhadoras; com a valorização profissional e salarial do professor; com sua autonomia intelectual, por meio de uma aguda consciência da problemática concreta da educação e da sala de aula e suas mediações e articulações com as relações sociais que marcam a sociedade capitalista.

A pedagogia como ciência da e para a práxis educativa, como também a didática como teoria do ensino enquanto prática social, síntese de múltiplas determinações, e que tem como tarefa organizar, intencionalmente, as situações e condições mobilizadoras e potencializadoras da apropriação dos conteúdos histórico-culturais, pelos estudantes. Esta condição é aqui considerada imprescindível para o desenvolvimento das qualidades humanas, em especial, do pensamento teórico.

A pedagogia apreende os fenômenos educativos no seu movimento contraditório e mediado pelos sujeitos historicamente situados e ativos e extrai daí sua especificidade e suas propriedades, indicando não apenas as questões regressivas da forma de ser da prática educativa (nas dimensões políticas, econômicas, sociais, ideoculturais), como também os elementos potencializadores da mudança. É, portanto, conhecimento sistemático, objetivo, intencional. 
Pimenta (2000) compreende que a pedagogia, ciência da educação, diferentemente das demais ciências da educação, toma a prática social da educação como ponto de partida e de chegada de suas investigações. Nesse sentido, é ciência da prática. A pedagogia, portanto, como ciência da prática da educação, é, ao mesmo tempo, constituída pelo fenômeno que estuda e o constitui. Isso aponta para uma inversão epistemológica, pois até então a pedagogia tem sido considerada um campo aplicado de discursos alheios à educação enquanto prática social. A ressignificação epistemológica da pedagogia se dá na medida em que toma a prática dos educadores como referência e para a qual significa

A didática como teoria do ensino enquanto prática social, síntese de múltiplas determinações que tem como tarefa organizar, intencionalmente, as situações e condições mobilizadoras e potencializadoras da apropriação dos conteúdos histórico-culturais, pelos estudantes. Esta condição é aqui considerada imprescindível para o desenvolvimento das qualidades humanas, em especial, do pensamento teórico. Contribuindo desse modo com a formação omnilateral da existência humana. Entendida como rica individualidade portadora de capacidades de produção e de gozo da riqueza material e espiritual.

\section{REFERÊNCIAS}

CANDAU, Vera Maria. Prefácio à Reconstrução da didática. In: OLIVEIRA, Maria Rita Neto Sales. A reconstrução da didática: elementos teórico-metodológicos. Campinas: Papirus, 1992.

CANDAU, Vera Maria. Da didática fundamental ao fundamental da didática. In: ANDRÉ, Marli E. A. D.; OLIVEIRA, Maria Rita N. S. (Orgs.). Alternativas no ensino de didática. Campinas: Papirus, 1997.

CANDAU, Vera Maria. A didática e a formação de educadores - da exaltação à negação: a busca da relevância. In: CANDAU, Vera Maria (Org.). A didática em questão. p. 13-24. Petrópolis: Vozes, 2000a.

FREITAS, Luis Carlos de. Crítica da organização do trabalho pedagógico e da didática. Campinas: Papirus, 1995. (Coleção Magistério: formação e trabalho pedagógico).

FRIGOTTO, Gaudêncio. A produtividade da escola improdutiva. Um (re)exame das relações entre educação e estrutura econômico-social capitalista. 3. ed. São Paulo: Autores Associados, 1989. (Coleção Educação contemporânea).

LIBÂNEO, José Carlos. Democratização da escola pública: a pedagogia crítico-social dos conteúdos. 7. ed. São Paulo: Loyola, 1985.

LIBÂNEO, José Carlos. Fundamentos teóricos e práticos do trabalho docente: estudo introdutório sobre pedagogia e didática. 1990. Tese (Doutorado em Educação) - Pontifícia Universidade Católica de São Paulo, São Paulo, 1990. 
LIBÂNEO, José Carlos. Didática. São Paulo: Cortez, 1994. (Coleção Magistério - Série Formação do professor).

LIBÂNEO, José Carlos. Educação: pedagogia e didática. O campo investigativo da pedagogia e da didática no Brasil: esboço histórico e buscas de identidade epistemológica e profissional. In: PIMENTA, Selma Garrido (Org.). Didática e formação de professores: percursos e perspectivas no Brasil e em Portugal. 3. ed. São Paulo: Cortez, 2000a. p. 77-130.

LUKÁCS, György. Socialismo e democratização. Escritos políticos, 1956-1971. Organização, introdução e tradução de Carlos Nelson Coutinho e José Paulo Netto. Rio de Janeiro: UFRJ, 2008. (Coleção Pensamento crítico, v. 11).

MARX, Karl. O capital: crítica da economia política. Tradução de Regis Barbosa e Regis R. Kothe. 3. ed. São Paulo: Nova Cultural, 1988a. (Coleção Os economistas, v. I).

MARTINS, P. Lúcia. O campo da didática: expressão das contradições da prática. In: EGGERT, Edla et al. (Orgs.). Trajetórias e processos de ensinar e aprender: didática e formação de professores: Livro 1. Simpósios desenvolvidos no XIV ENDIPE (Encontro Nacional de Didática e Prática de Ensino). Porto Alegre: EDIPUCRS, 2008., p. 585, 601.

OLIVEIRA, Maria Rita Neto Sales. A reconstrução da didática: elementos teóricometodológicos. Campinas: Papirus, 1992.

OLIVEIRA, Maria Rita Neto Sales. Elementos teóricos-metodológicos na construção e na reconstrução da didática. Educação em Revista: Revista da Faculdade de Educação UFMG, ano VI, n. 14, Belo Horizonte: UFMG, 1991.

OLIVEIRA, Maria Rita Neto Sales. 20 anos de ENDIPE. In: CANDAU, Vera Maria et al. Didática, currículo e saberes escolares. Rio de Janeiro: DP\&A Editora, 2000.p. 161-176.

OLIVEIRA, Maria Rita Neto Sales; ANDRÉ, Marli Eliza D. A. A prática do ensino de didática no Brasil: introduzindo a temática. In: OLIVEIRA, Maria Rita Neto Sales; ANDRÉ, Marli Eliza D. A. (Orgs.). Alternativas no ensino de didática. 6. ed. Campinas: Papirus, 1997. p. 7-18.

PAULO NETTO, José; BRAZ, Marcelo. Economia política: uma introdução crítica. São Paulo: Cortez, 2006.

PIMENTA, Selma Garrido. Para uma ressignificação da didática. In: PIMENTA, Selma Garrido. Didática e formação de professores: percursos e perspectivas no Brasil e em Portugal. 3. ed. São Paulo: Cortez, 2000.

PIMENTA, Selma Garrido. Panorama atual da didática no quadro das ciências da educação: educação, pedagogia e didática. In: PIMENTA, Selma Garrido (Org.). Pedagogia, ciência da educação. 3. ed. São Paulo: Cortez, 2001, p. 39-70.

PIMENTA, Selma Garrido. O estágio na formação de professores: unidade teoria e prática? 6. ed. São Paulo: Cortez, 2005. 
SAVIANI, Dermeval. Educação socialista, pedagogia histórico-crítica e os desafios da sociedade de classes. In: LOMBARDI, José Claudinei; SAVIANI, Dermeval (Orgs.). Marxismo e educação: debates contemporâneos. Campinas: Autores Associados; HISTEDBR, 2005a.

SAVIANI, Dermeval. Pedagogia histórico-crítica: primeiras aproximações. 9. ed. São Paulo: Autores Associados, 2005b.

SAVIANI, Dermeval. As concepções pedagógicas na história da educação brasileira: 20 anos do HISTEDBR: navegando na história da educação. CD-ROM, 2006. Disponível em: <http://www.histedbr.fae.unicamp.br/navegando/artigos_frames/artigo_036.html>. Acesso em: 17 jul. 2009.

SAVIANI, Dermeval. História das ideias pedagógicas no Brasil. Campinas: Autores Associados, 2007. (Coleção Memória da educação).

SAVIANI, Dermeval. A pedagogia no Brasil: história e teoria. Campinas: Autores Associados, 2008a. (Coleção Memória da educação).

SAVIANI, Dermeval. Escola e democracia. Edição comemorativa. Campinas: Autores Associados, 2008b. (Coleção Educação contemporânea).

SCHMIED-KOWARZIK, Wolfdietrich. Pedagogia dialética de Aristóteles a Paulo Freire. São Paulo: Brasiliense, 1983.

VEIGA, Ilma Passos Alencastro. A prática pedagógica do professor de didática. 2. ed. Campinas: Papirus, 1992.

WACHOWICZ, Lílian Anna. O método dialético na didática. 2. ed. Campinas: Papirus, 1991.

\section{SOBRE A AUTORA:}

\section{Lenilda Rêgo Albuquerque de Faria}

Doutor(a) em Educação pela Faculdade de Educação da Universidade de São Paulo (FEUSP), São Paulo-SP. Docente e pesquisadora do Centro de Educação Letras e Artes (CELA) e do Programa de Pós-Graduação em Educação (PPGE) na Universidade Federal do Acre (UFAC), Rio Branco-AC. É membro do Grupo de Estudos e Pesquisa sobre Formação de Educadores (GEPEFE/FEUSP). E-mail: lenildafaria@uol.com.br

(iD https://orcid.org/0000-0002-8971-600X 